\title{
Ficção em Tempos de Pandemia: uma análise de Um Diário do Ano da Peste de Daniel Defoe
}

\author{
Fiction in Times of Pandemic: an analysis of Daniel Defoe's "A Journal of the Plague \\ Year"
}

\section{Ítalo Lins Lemos*}

Resumo: Analisarei o romance Um Diário do Ano da Peste de Daniel Defoe como sendo um experimento mental que nos fornece prescrições consistentes sobre como agir em tempos de pandemia. Para mostrar que obras de ficção não possuem apenas valor estético, mas também um caráter cognitivo, defenderei o cognitivismo crítico e sustentarei desse modo que os ganhos cognitivos que temos a partir de uma obra de ficção acontecem em uma reflexão posterior à experiência imediata com a obra. Em seguida, argumentarei que a ficção possui uma vantagem heurística frente à filosofia e às ciências, pois uma narrativa ficcional fornece ao espectador uma perspectiva privilegiada dos fatos ou dos pensamentos de uma personagem. Essa perspectiva pode sensibilizar o espectador e fazê-lo ter empatia pela personagem que sofre; e isso pode funcionar, em tempos de pandemia, como uma defesa das medidas de prevenção, a exemplo do isolamento social.

Palavras-chave: Fícção; Pandemia; Cognitivismo crítico; Entendimento; Empatia; Isolamento Social

Abstract: I will analyze Daniel Defoe's A Journal of the Plague Year as a thought experiment that gives us prescriptions on how to act in times of pandemic. In order to show that works of fiction do not possess aesthetic value only, but also a cognitive character, I will defend critic cognitivism and thus hold that the cognitive gains one has from fiction occur in a reflective aftermath in relation to the immediate experience with the work. Then I will argue that fiction has a heuristic vantage in comparison to philosophy and the sciences because a fictional narrative provides the spectator a privileged perspective on the facts and on the character's thoughts. Such a perspective might sensitize the spectator and make him empathetic with a character who suffers; and that may function, in times of pandemic, as a defense of the prevention measures, such as social distancing.

Keywords: Fiction; Pandemic; Critical cognitivism; Understanding; Empathy; Social distancing

\section{Introdução}

A pandemia causada pelo coronavírus alterou radicalmente as nossas atividades cotidianas. As instituições de ensino suspenderam os seus calendários de aula ou adotaram o ensino à distância, os centros comerciais das metrópoles mundiais fecharam e há um fluxo bastante reduzido de veículos automotivos e pessoas trafegando nas cidades. Esse cenário se instaurou porque adotamos a medida considerada mais eficaz para desacelerar a disseminação do vírus: o isolamento social. Espera-se que a redução do contágio evite que um grande número de pessoas necessite de auxílio hospitalar concomitantemente - o que causaria o colapso dos sistemas de saúde ao redor do mundo ${ }^{1}$. Porém, uma vez isoladas, as

\footnotetext{
${ }^{1}$ WIGHTON, Individual response to COVID-19 'as important as' government action.
} 
pessoas têm se defrontado com a ansiedade, com o receio de adoecer e com o temor de perder algum amigo ou ente querido em decorrência da COVID-19.

Seja com o objetivo de afastar o tédio, ganhar capital cultural ou apenas por entretenimento, muitos neste momento têm buscado refúgio nas obras de ficção que retratam epidemias e pandemias. Obras clássicas da literatura mundial como $O$ Decamerão (1353) de Giovanni Boccaccio, A Máscara da Morte Rubra (1842) de Edgar Allan Poe e A Peste (1947) de Albert Camus, por exemplo, têm sido revisitadas com frequência. Entretanto, a obra literária que tem sido mais requisitada é Um Diário do Ano da Peste do escritor inglês Daniel Defoe. Um Diário do Ano da Peste, que tornou ficcionais os acontecimentos marcantes da epidemia de peste bubônica que ocorreu em Londres entre os anos 1665 e 1666, atravessou os séculos e se tornou um sucesso de vendas durante essa pandemia, chegando ao ponto de sua edição produzida pela Penguin Books ter se esgotado nas livrarias da Inglaterra².

Mas em que sentido uma obra de ficção sobre uma epidemia que ocorreu em Londres no século XVII pode ser relevante atualmente? Podemos aprender algo sobre a pandemia de coronavírus a partir de Um Diário do Ano da Peste? Para responder essas questões, adotarei o cognitivismo crítico desenvolvido por Peter Kivy ${ }^{3}$, Nöel Carroll ${ }^{4}$ e John Gibson ${ }^{5}$ e defenderei que podemos ter ganhos cognitivos quando analisamos uma obra de ficção em um contexto externo a ela. Nesse sentido, uma obra de ficção pode ser tomada como um experimento mental que, uma vez transposto e confrontado com o mundo empírico, pode servir como um recurso heurístico e apologético para que certas medidas sejam tomadas - como, nesse caso, o respeito às medidas de isolamento social. A ficção possui uma vantagem didática em relação à filosofia e à ciência na medida em que consegue sensibilizar o leitor e fazê-lo sentir empatia por aqueles que sofrem, embora os ganhos cognitivos resultem apenas quando a ficção converge com a filosofia, a ciência ou outra área do conhecimento.

\section{A natureza do cognitivismo crítico na literatura}

O debate sobre o caráter cognitivo e didático das obras de ficção - isso é, a questão de se podemos adquirir algum tipo de entendimento sobre o funcionamento do mundo empírico através, por exemplo, da literatura e do cinema - é tão antigo quanto o diálogo entre Sócrates e Íon ou as críticas de Platão aos poemas de Homero. Ainda no cenário atual da filosofia, se de um lado parece consensual que as obras de ficção possuem valor estético (como beleza), por outro lado há controvérsias sobre o seu caráter cognitivo. No presente artigo defenderei o cognitivismo crítico e analisarei como podemos ter um melhor entendimento sobre o funcionamento do mundo empírico e da nossa cultura através da ficção.

Comecemos a análise ao identificar esquematicamente alguns dos fatores que levam certos filósofos, como Peter Lamarque e Stein Haugom Olsen ${ }^{6}$, a rejeitar uma posição cognitivista em Filosofia da Arte. Reconhecerei que todos esses fatores são plausíveis e adequados na análise da natureza da ficção, porém são compatíveis com a perspectiva cognitivista crítica que apresentarei adiante.

Primeiramente, a ficção é uma atividade imaginativa. Lewis Carroll, por exemplo, ao escrever Alice no País das Maravilhas, não se comprometeu com a existência concreta de coelhos falantes, chapeleiros malucos ou poções mágicas em nosso mundo. Nem mesmo Franz Kafka, ao escrever A Metamorfose, pretendia afirmar que em algum lugar de Praga existiu um caixeiro viajante chamado 'Gregor Samsa' que em certa manhã se transformou literalmente

\footnotetext{
${ }^{2}$ PEPINSTER, Daniel Defoe's Journal of the Plague Year being reprinted after selling out.

${ }^{3}$ KIVY, Philosophies of Arts: An Essay in Differences.

${ }^{4}$ CARROLL, The Wheel of Virtue: Art, Literature, and Moral Knowledge.

${ }^{5}$ GIBSON, Interpreting Words, Interpreting Worlds.

${ }^{6}$ Cf. LAMARQUE \& OLSEN, Truth, Fiction and Literature: A Philosophical Perspective.
} 
em um inseto monstruoso. Seja a Alice, seja a transformação de Samsa, os objetos e os acontecimentos de uma obra de ficção foram imaginados e tornados públicos por seus respectivos autores através de livros, filmes ou peças de teatro. Portanto, o autor não possui necessariamente um compromisso com a natureza do mundo empírico ao escrever uma obra de ficção, ou seja, os artistas não precisam estar em consonância com as nossas melhores teorias científicas. Em alguns casos, como nos filmes do diretor Alejandro Jodorowsky, quanto mais a imaginação de um autor burlar as leis da física, tanto melhor para a originalidade e peculiaridade de sua obra.

Afinal de contas, o que configuraria a segunda razão contra a adoção de uma posição cognitivista, dizer que uma obra é ficcional significa que as declarações realizadas por um autor ao compor a sua obra não se direcionam (no sentido de uma 'direction of fit') ao mundo empírico. Ao não se direcionarem ao mundo empírico, essas declarações são responsáveis pela criação de objetos e acontecimentos ficcionais uma vez que, como John Gibson argumenta: "uma marca da fala cotidiana é o uso da linguagem para descrever o mundo; uma marca da literatura é o uso da linguagem para criar um mundo"7. Desse modo, a transformação de Gregor Samsa em um inseto monstruoso ou o encolhimento de Alice após a ingestão de uma substância mágica são acontecimentos que se sucederam em "mundos ficcionais" - e não propriamente no mundo empírico - e Gregor Samsa e Alice são personagens ficcionais - e não propriamente indivíduos de carne e osso ${ }^{8}$.

Uma terceira razão, que está associada às duas anteriores, é a circunstância de um autor de ficção não ser um cientista. 0 escritor de uma novela, o roteirista de um filme ou o diretor de uma peça não trabalham em um laboratório de química, nem devem necessariamente descrever como o mundo empírico se estrutura. Essa é inclusive a razão pela qual é inapropriado sustentar que as declarações que um autor realiza em sua obra de ficção sejam mentirosas ou falsas, uma vez que o autor está se referindo a um mundo ficcional. Consequentemente, o indivíduo que ao ler Alice no País das Maravilhas afirmar que essa obra não passa de um conjunto de mentiras, na medida em que coelhos não conseguem se expressar em inglês ou em português, não compreendeu os mecanismos e a dinâmica de uma obra de literatura pois, como se torna evidente nesse exemplo, demanda do romance um rigor metafísico e epistêmico que não precisa ser atendido pela ficção.

Não obstante, como podemos sustentar com plausibilidade a tese de que podemos ter ganhos de entendimento a partir da ficção? O cognitivismo crítico consiste na tese de que podemos aprender com a literatura ou com o cinema em uma reflexão posterior, o que John Gibson chama de 'reflective aftermath' ${ }^{9}$. Trata-se, portanto, de uma perspectiva externalista da ficção, uma vez que o entendimento é gerado através do nosso contato interpretativo com a obra. Ou seja, como aponta Nöel Carroll: "o argumento, contudo, acontece na mente do leitor, seja enquanto processa o texto ou, o que é mais provável, durante a sua reflexão posterior (seja em uma conversa consigo ou com outros)"10. No entanto, a que forma de entendimento os cognitivistas críticos estão se referindo?

Uma primeira hipótese, que pode ser facilmente analisada, é um entendimento interno à obra. Parece ser evidente que temos esse tipo de entendimento, pois podemos saber qual é o gênero épico (se romance, novela, conto, etc), o gênero lírico (se soneto, elegia, ode, etc) e o gênero dramático (se comédia, tragédia, etc) de uma obra. Podemos saber ainda, nesse caso mesmo sem auxílio de um crítico literário, quantos capítulos, seções ou atos uma obra possui; podemos descobrir quem é o narrador, quais são as personagens e quais são as atividades que elas realizam ou sofrem durante a narrativa. Entretanto, não é desse tipo de entendimento que estamos falando quando tratamos do cognitivismo crítico. Por ora não estamos

\footnotetext{
${ }^{7}$ GIBSON, Interpreting Words, Interpreting Worlds, 443, tradução nossa.

${ }^{8}$ LEMOS, A Metafísica e a Semântica da Ficção: Uma Abordagem Artefactual, capítulo 1.

${ }^{9}$ GIBSON, Cognitivism and the Art, 581.

${ }^{10}$ CARROLL, The Wheel of Virtue: Art, Literature, and Moral Knowledge, 14.
} 
interessados em saber o que é o caso de acordo com uma história (ou seja, acerca de algum elemento 'interno'), mas em saber o que podemos transpor da ficção para o mundo empírico.

Estamos, portanto, buscando um entendimento 'externo' à obra de ficção. Em outras palavras, não estamos procurando o que podemos dizer sobre gêneros ou estruturas narrativas, mas o sentido que podemos atribuir a uma obra como um todo e como esse sentido se relaciona com o mundo em que vivemos. Assim, buscamos compreender em que sentido Bartleby, o Escrivão de Herman Melville e A Metamorfose de Kafka são novelas sobre o sentimento de alienação que a vida moderna impõe não a personagens ficcionais, mas a indivíduos materiais - caso contrário, essas obras seriam triviais e desinteressantes.

Peter Kivy chama atenção para a circunstância de que podemos tomar as obras de ficção como "hipóteses vivas, na forma de afirmações temáticas gerais as quais o leitor, como parte da experiência literária, busca confirmar ou desconfirmar através de pensamentos ou ações"11. Nessa acepção, uma obra de ficção pode ser tomada como um experimento mental: um cenário imaginário em que investigamos o campo das possíveis consequências estabelecidas por determinadas premissas. 0 recurso a experimentos mentais (ou experimentos de pensamento) é comum tanto na filosofia como nas ciências: encontramos na filosofia a narrativa sobre o Anel de Giges na República de Platão, a hipótese do gênio maligno nas Meditações sobre Filosofia Primeira de Descartes e a história da Terra Gêmea de Hilary Putnam em O Significado de 'Significado'; enquanto nas ciências nos deparamos com o gato de Schrödinger, os exercícios sobre o movimento dos corpos em superfícies que não possuem atrito e a concepção de pontos que não possuem extensão.

Saliento, todavia, que a ficção não é uma expressão artística que é instrumentalizada por definição, mas que essa é uma atitude que comumente tomamos diante dela. Uma obra de ficção pode ser criada para deleite estético, para a expressão de uma cultura, para ganho de dinheiro ou simplesmente para nada. Nesse caso, uma das atitudes que podemos tomar diante da ficção é torná-la um experimento mental para analisarmos o comportamento humano no mundo empírico. Peter Kivy sugere, como notamos na citação do parágrafo acima, que os experimentos de pensamento que extraímos de obras de ficção devem ser confirmados ou desconfirmados, i.e., que nesses casos a obra não deve ser tomada em seu valor de face, mas a partir de uma análise crítica. Dado que os mundos ficcional e empírico não são o mesmo, embora o mundo ficcional seja derivado das nossas práticas literárias ou cinematográficas no mundo empírico, o espectador deve transpor o conteúdo daquele para esse e ter as ferramentas conceituais e a sensibilidade científica (ou antropológica, sociológica, filosófica, etc) requerida para realizar essa transposição - que nem sempre é bem-sucedida. Felizmente por vezes, como é o caso de Um Diário do Ano da Peste, somos presenteados com a ocasião em que o próprio autor de ficção é um indivíduo esclarecido que alimentou a sua narrativa com dados científicos ou históricos adequados em relação ao mundo empírico. Não obstante, devemos ter muita cautela ao realizar essa transposição pois intentamos extrair de $A$ Metamorfose, por exemplo, a tese sobre o sentimento de alienação inerente ao mundo moderno (que por sua vez é uma tese sociológica relevante) ao invés de uma tese sobre a possibilidade de seres humanos se transformarem literalmente em insetos monstruosos (que por sua vez é uma tese biológica absurda). Portanto, são os leitores críticos que fazem os mundos ficcional e empírico convergirem; e é na esfera pública que os conteúdos transpostos devem ser julgados como sendo plausíveis ou não.

Enquanto experimento mental, a ficção tem uma enorme vantagem em relação aos tratados filosóficos e artigos científicos: a sua capacidade heurística. Ao colocar o leitor em uma posição privilegiada, seja em relação aos fatos ou aos pensamentos das personagens, uma obra de ficção fornece cores vivazes a uma teoria que, em um momento interpretativo posterior, pode ser sustentada (caráter apologético) ou contrariada (caráter cético). Um

${ }^{11}$ KIVY, Philosophies of Arts: An Essay in Differences, 127, tradução nossa. 
recurso heurístico ou didático eficiente é a sensibilização do espectador, que por sua vez se coloca em uma posição empática ou simpática em relação a uma personagem. Por 'empatia' entendo a nossa capacidade de sentirmos algo não por alguém, mas como alguém e em decorrência da situação em que esse alguém se encontra: é o mesmo que "colocar-se no lugar de outrem"; por 'simpatia' compreendo um estado afetivo que é semelhante ao da empatia, mas relativo ao sofrimento de outrem ${ }^{12}$. Ao estar na posição de alguém que sofre, nesse caso, o sofrimento de uma personagem, o espectador é levado a considerar a causa desse sofrimento e assim compreender como seria estar em uma posição como essa.

Portanto, é nessa esteira em que analisarei Um Diário do Ano da Peste de Daniel Defoe e o relacionarei à pandemia de coronavírus que estamos enfrentando atualmente. Mostrarei em que sentido podemos tomar esse romance como um experimento mental e quais são os recursos heurísticos utilizados por Defoe que, em um contexto externo ao da própria obra, funcionam como um instrumento para a sensibilização do sujeito que, a partir da leitura do romance, pode se tornar mais empático ou simpático frente aos que sofrem por conta de uma enfermidade. Por fim, desde que se tenha o interesse em atenuar o sofrimento de outrem, Um Diário do Ano da Peste pode ser interpretado como uma defesa das medidas de isolamento social que são recomendadas pelos profissionais de saúde não apenas em um mundo ficcional, mas também no mundo empírico.

\section{Um Diário do Ano da Peste e o isolamento social}

Daniel Defoe (1660-1731) transpôs um acontecimento histórico para a ficção em um Um Diário do Ano da Peste. Entre os anos 1665 e 1666, uma epidemia causada pela Yersinia pestis alterou radicalmente as atividades cotidianas dos cidadãos londrinos. Estima-se que cerca de 100 mil pessoas (o equivalente a 15\% da população da cidade na época) tenham falecido em função da peste ${ }^{13}$. Como podemos observar a partir da data de nascimento de Defoe, o autor tinha apenas cinco anos quando a epidemia começou a assolar a Inglaterra. Contudo, acredita-se que o escritor tenha romantizado as vivências de seu tio Henry Foe (sendo essa possivelmente a razão pela qual o narrador da obra é identificado pelas iniciais 'H.F.'), além de haver consultado os documentos oficiais (como os Bills of Mortality, uma espécie de obituário) e ter feito uso dos relatos orais de outros cidadãos que sobreviveram à epidemia ${ }^{14}$.

Os protagonistas da obra são a peste, a cidade de Londres e o narrador. As demais personagens (como o pescador ou o famoso pedinte) aparecem brevemente, seja porque estão abandonando a cidade de Londres para fugir da peste, seja porque a peste os abateu. Um Diário do Ano da Peste não é, assim, uma obra sobre um indivíduo humano, mas sobre uma sociedade que enfrenta uma doença desconhecida e avassaladora. A obra se inicia com os primeiros burburinhos sobre a chegada da peste a Londres, o que imediatamente causa uma debandada dos aristocratas para a zona rural da Inglaterra - o que evidencia que os menos abastados sofreram ainda mais intensamente por conta da peste - , em seguida o narrador descreve o sofrimento dos londrinos enfermos até o ponto Shakespeariano em que "tudo está bem quando acaba bem" e a peste é vencida.

Um Diário do Ano da Peste foi tão cuidadosamente alimentado por fontes históricas confiáveis que por algum tempo houve uma querela sobre o estatuto ontológico da obra, isso é, se ela seria um romance histórico ou um trabalho historiográfico romantizado ${ }^{15}$. Frank Ellis relata que a verossimilhança da obra em relação aos acontecimentos históricos é tão notável,

\footnotetext{
12 GIBSON, Empathy, 234-5.

${ }^{13} \mathrm{BBC}$, Voices of the Powerless: Boils and Buboes.

${ }^{14}$ Cf. ELLIS, A Journal of the Plague Year by Daniel Defoe.

${ }^{15} \mathrm{Cf}$. MAYER, The Reception of a Journal of the Plague Year and the Nexus of Fiction and History in the Novel.
} 
e as descrições sobre os sintomas da doença são tão detalhadas e precisas, que epidemiologistas como Fabian Hirst usaram o romance como evidência de que a primeira fase da peste em Londres foi tanto pneumônica como bubônica; enquanto o professor Paul Slack recorre à obra para destacar as medidas sanitárias empregadas pelos cidadãos para combater a peste como, por exemplo, o isolamento social e o uso de vinagre como um produto com efeito antisséptico ${ }^{16}$.

Começarei a minha análise do romance enfatizando as diferenças entre o que é narrado e o estado de coisas atual relacionado ao coronavírus. Em primeiro lugar, há uma enorme diferença na letalidade das duas doenças: enquanto o índice de letalidade da peste ficava entre $70 \%$ e $100 \%$, um estudo compartilhado pelo Imperial College mostrou que o índice da COVID-19 se encontra entre 0,5\% e $1 \%$ dos casos - apesar da falta de testes prejudicar a exatidão das estatísticas ${ }^{17}$. Logo, embora seja preocupante, o coronavírus é consideravelmente menos letal que a Yersinia. Além disso, a peste era causada por uma bactéria que se encontrava em algumas pulgas que parasitavam os ratos (embora a peste pneumônica também possa ser transmitida pelas secreções de humanos infectados), enquanto a COVID-19 é causada por um vírus. Em segundo lugar, também há uma diferença no estado das ciências dos séculos XVII e XXI: foi apenas no final do século XIX, por exemplo, que os cientistas descobriram que a peste era causada por uma bactéria que se encontrava em pulgas, enquanto hoje sabemos até mesmo os detalhes da sequência genética do coronavírus - embora ainda não tenhamos encontrado uma cura para a doença causada por esse vírus. Em terceiro lugar, por mais precisas que sejam as descrições de Defoe em seu romance, $U m$ Diário do Ano da Peste é uma obra de ficção - e não somos habitantes de um mundo ficcional. Dessa maneira, é necessário realizar a transposição do que é o caso de acordo com a ficção para o mundo empírico.

As semelhanças entre essa narrativa e o atual estado de coisas também é notável. Com a chegada da doença, as atividades culturais foram imediatamente suspensas e as atividades comerciais enfrentaram diversas restrições ${ }^{18}$ em função da recomendação de que todos aderissem ao isolamento social ${ }^{19}$. Apesar disso, várias pessoas o desrespeitaram ${ }^{20}$, o que ocasionou um aumento do número de infectados ${ }^{21}$, especialmente porque aqueles assintomáticos subestimaram a letalidade da doença e, nessa atitude egoísta, auxiliaram na disseminação da enfermidade ${ }^{22}$. Os cidadãos começaram então a usar máscaras para ir aos mercados a fim de comprar mantimentos ${ }^{23}$, porém essa medida não foi suficiente para desacelerar o contágio. Ademais, as cidades não possuíam uma estrutura hospitalar robusta o suficiente para atender a grande quantidade de infectados ${ }^{24} \mathrm{e}$, fatalmente, diversos profissionais de saúde faleceram em função da exposição constante ao patógeno ${ }^{25}$. Em pouco tempo os cadáveres começaram a se empilhar e foram enterrados em valas comuns, pois os cemitérios haviam alcançado a sua capacidade máxima ${ }^{26}$. Houve ainda um acompanhamento semanal do número de mortos $^{27}$ e o aparecimento de charlatães que prescreviam remédios

\footnotetext{
${ }^{16}$ ELLIS, A Journal of the Plague Year by Daniel Defoe, 79-80.

${ }^{17}$ VERITY; OKELL; DORIGATTI; et al, Estimates of the Severity of Coronavirus Disease 2019: A Model-based Analysis.

${ }^{18}$ DEFOE, A Journal of the Plague Year, 31.

${ }^{19}$ Idem, ibidem, 168, 211, 265.

${ }^{20}$ Idem, ibidem, 53.

${ }^{21}$ Idem, ibidem, 265.

${ }^{22}$ Idem, ibidem, 191.

${ }^{23}$ Idem, ibidem, 211.

${ }^{24}$ Idem, ibidem, 266.

${ }^{25}$ Idem, ibidem, 259.

${ }^{26}$ DEFOE, A Journal of the Plague Year, 62.

${ }^{27}$ Idem, ibidem, 5.
} 
sem eficácia ou curas milagrosas ${ }^{28}$. Os cidadãos mais pobres e aqueles que perderam os seus empregos por conta da crise sanitária receberam um pequeno auxílio de custo do Estado ${ }^{29}$, mas a catástrofe econômica foi inevitável ${ }^{30}$ por conta dos embargos comerciais que se sucederam $^{31}$.

O narrador, ao se deparar com o cenário calamitoso, recomendou que os cidadãos seguissem as medidas sanitárias determinadas pelos profissionais de saúde pois, em uma situação na qual não se tinha uma cura para uma doença que se espalhava sem controle, os recursos mais eficientes seriam a saída do epicentro do contágio e o isolamento social:

Dado o caráter de todas essas observações eu devo dizer que, apesar da providência divina parecer ter me sugerido que eu fizesse o contrário, a minha opinião é que - e eu devo pronunciá-la como uma prescrição - o melhor remédio contra a peste é fugir dela ${ }^{32}$.

Mas prescrições como essa são comumente inócuas na medida em que, caso adotemos uma postura humeana sobre a natureza humana, a razão é uma mera ancila das paixões. Dessa maneira, Defoe primeiramente apresentou argumentos para convencer, mas em seguida encontrou meios de comover o leitor para fazê-lo acreditar que o estado de coisas descrito em seu romance era verdadeiramente assustador. Citarei uma passagem da obra que ilustra o seu apelo à empatia:

Eu me lembro - e enquanto escrevo essa história eu acredito que me recordo até mesmo do próprio barulho - de certa mulher que possuía uma única filha: uma jovem donzela com cerca de 19 anos de idade e que possuía uma fortuna bastante considerável. Elas eram as únicas inquilinas da casa que habitavam. A jovem mulher, a sua mãe e a empregada doméstica se ausentaram por alguma ocasião, não me lembro exatamente para que fim, e deixaram a casa destrancada. Mais ou menos após duas horas elas retornaram e a jovem senhorita se queixou que não estava se sentindo bem; em quinze minutos ela vomitou e teve uma dor de cabeça violenta. "Meu Deus", dizia a sua mãe com um pavor terrível, "a minha filha não tem a enfermidade!". A dor na cabeça da jovem mulher aumentava, o que fez com que a sua mãe ordenasse que aquecessem a sua cama, tendo a sua mãe a colocado em sua cama e preparado o processo para que ela suasse - pois esse era o remédio comum a ser tomado quando as primeiras apreensões da enfermidade começavam.

Enquanto a cama estava arejando, a mãe despiu a jovem mulher e enquanto esta se deitava na cama a sua mãe olhou para o seu corpo com uma vela e descobriu imediatamente que lá havia os sinais da peste por dentro de suas coxas. A mãe, sem conseguir se conter, deixou a vela cair ao chão e grunhiu de uma maneira tão assustadora que poderia aterrorizar o coração mais forte do mundo. Sequer foi apenas um grito ou um urro pois, o pavor tendo arrasado as suas energias, ela primeiramente desmaiou e em seguida se recuperou e correu por toda a casa: subiu e desceu as escadas como alguém distraído pois ela realmente estava distraída - e continuou guinchando e chorando convulsivamente por várias horas, destituída de qualquer sentido ou, ao menos, sem governo dos seus sentidos; e, de acordo com o que me contaram, nunca voltou a ser completamente ela mesma. Em relação à jovem donzela, ela era um cadáver naquele momento, pois a gangrena que ocasionou as marcas

\footnotetext{
${ }^{28}$ Idem, ibidem, 257.

${ }^{29}$ Idem, ibidem, 269.

${ }^{30}$ Idem, ibidem, 215.

${ }^{31}$ Idem, ibidem, 270.

${ }^{32}$ Idem, ibidem, 198, tradução nossa.
} 
tinham se espalhado por todo o seu corpo e ela morreu em menos de duas horas. Mas ainda assim a sua mãe continuou chorando convulsivamente, sem nada saber sobre a sua filha, mesmo várias horas após a sua morte. Faz tanto tempo que não tenho certeza, mas acredito que a mãe nunca se recuperou e morreu duas ou três semanas após esse acontecimento ${ }^{33}$.

A sucessão dos eventos é chocante, especialmente porque a maestria literária de Defoe faz transparecer - tendo em vista que os acontecimentos são narrados em sua completude em apenas dois parágrafos - a rapidez com que a doença se instala no organismo de um indivíduo e o leva à morte de modo doloroso física e emocionalmente. Um Diário do Ano da Peste é impactante pois nele encontramos diversos relatos semelhantes a esse da passagem anterior, como o de um homem enfermo que, por conta das dores causadas pelas inflamações que são características da peste, cometeu suicídio ao se amarrar em sua própria cama e atear fogo sobre $\mathrm{si}^{34}$; ou ainda a história de um sujeito que perdeu o controle de suas faculdades mentais e correu nu e em êxtase pela cidade de Londres ${ }^{35}$, dentre outros acontecimentos marcantes.

Esses eventos "muito, muito, muito terríveis, que nenhuma língua pode expressar" 36 , que levam o narrador a se perguntar "o que pode ser dito para representar a miséria dessa época de maneira mais vivaz para o leitor ou dá-lo uma ideia mais perfeita dessa imensa angústia?"37, podem ser transpostos para o mundo empírico e colocados em paralelo com o sofrimento daqueles que são acometidos pelos casos graves de COVID-19. Os relatos sobre os pacientes que chegam aos hospitais se debatendo como "peixes fora do aquário", uma vez que o coronavírus pode destruir os pulmões do infectado e, portanto, a sua capacidade respiratória, são ainda mais horripilantes porque fazem parte da vida real ${ }^{38}$. Os familiares dos enfermos também se afligem, uma vez que aqueles que ocupam um leito na unidade de tratamento intensivo e são entubados para serem conectados a um respirador devem ficar em isolamento e sem contato com o mundo fora do hospital. Alguns profissionais de saúde têm se sensibilizado e usado a tecnologia a favor dos pacientes e permitido a realização de videoconferências entre os enfermos e a sua família através de tablets ${ }^{39}$.

Nesse sentido, o que conecta Um Diário do Ano da Peste ao mundo empírico não é apenas uma bactéria ou um vírus, mas a própria condição humana. Ao reconhecermos que somos seres frágeis, mortais e sem controle do nosso destino e ao nos colocarmos em uma posição empática frente a aqueles que sofrem, teremos o entendimento de que devemos fazer tudo o que for possível para diminuir a dor de outrem. Nesse momento tão complicado da história humana - assim como foi para os londrinos em 1665 e 1666 - podemos fazer algo que é na verdade bastante simples e que é recomendado tanto na ficção como pela ciência: respeitar o isolamento social para desacelerar o contágio e, assim, permitir que os gravemente enfermos tenham acesso a um atendimento hospitalar.

\section{Considerações finais}

A filosofia é uma atividade que, assim como sugere a famosa encarnação da ave de Minerva, é comumente realizada após o desfecho do evento que está sob análise. Os filósofos precisam, em certo sentido, de um distanciamento temporal e da vantagem do hindsight para

\footnotetext{
${ }^{33}$ DEFOE, A Journal of the Plague Year, 55-6, tradução nossa.

${ }^{34}$ Idem, ibidem, 175.

${ }^{35}$ Idem, ibidem, 176.

${ }^{36}$ Idem, ibidem, 60, tradução nossa.

${ }^{37}$ Idem, ibidem, 176, tradução nossa.

38 ONGARATTO, Coronavírus: "As pessoas chegam feito peixe fora do aquário, morrendo sem ar. Pedi afastamento".

${ }^{39}$ COLLUCCI, Hospitais usam tablets e robôs para aproximar pacientes com coronavírus de famílias.
} 
investigar um evento sob diversas perspectivas e, assim, ter a clareza necessária para julgar a sua real extensão e significado. Essa é uma das razões pelas quais uma análise sobre a natureza e as consequências da pandemia causada pelo coronavírus consiste em um verdadeiro desafio intelectual. Mas, mesmo que cada evento tenha as suas particularidades, essa não é a primeira pandemia atravessada pela humanidade. Podemos olhar com atenção para a história, para a ficção e para as ciências em momentos de dificuldade e, desejando promover o bem-estar de outrem, tomar as decisões adequadas.

0 mundo se transformou radicalmente nos últimos três séculos. Mas uma obra recebe o rótulo de 'clássico' justamente porque podemos extrair dela aprendizados que transcendem o contexto em que ela foi concebida. Como afirma Peter Kivy: "um mundo sem os teatrólogos gregos, sem Shakespeare e Cervantes, Dostoiévski e Tólstoi, Austen e Goethe seria um mundo em que um enorme número de pessoas permaneceriam ignorantes em relação a várias especulações filosóficas" 40 . Arrisco-me a argumentar que podemos incluir Daniel Defoe nesse seleto grupo especialmente agora, na medida em que Um Diário do Ano da Peste pode nos dar algum entendimento sobre como agir em tempos de pandemia. Finalmente, uma vez que ainda estamos à espera de uma cura para a COVID-19, resta-nos respeitar o isolamento social — o que pode ser promovido através da empatia.

\section{Agradecimentos}

Gostaria de agradecer especialmente a Gisely dos Santos Ganoza, Eduardo Souza, Raoni Wohnrath Arroyo e Cristian Santiago pela discussão e revisão do presente artigo.

\section{Referências}

BBC. Voices of the Powerless: Boils and Buboes. Londres, 2002. Disponível em: <http://www.bbc.co.uk/radio4/history/voices/voices salisbury.shtml>. Acesso em: 15 de abril de 2020.

CARROLL, N. The Wheel of Virtue: Art, Literature, and Moral Knowledge. The Journal of Aesthetics and Art Criticism, v. 60, n. 1, p. 3-26, 2002.

COLLUCCI, C. Hospitais usam tablets e robôs para aproximar pacientes com coronavírus de famílias. São Paulo: Folha de São Paulo. Disponível em: <https://www1.folha.uol.com.br/equilibrioesaude/2020/04/hospitais-usam-tablets-e-robospara-aproximar-pacientes-com-coronavirus-de-familias.shtml>. Acesso em 28 de abril de 2020.

DEFOE, D. A Journal of the Plague Year. Nova Iorque: Longmans, Green, and Co., 1722/1896.

ELLIS, F. A Journal of the Plague Year by Daniel Defoe. The Review of English Studies, v. 45, n. 177, p. 67-82, 1994.

GIBSON, J. Empathy. In: Carrol, N \& Gibson, J. The Routledge Companion to Philosophy of Literature, p. 234-246, 2016.

GIBSON, J. Cognitivism and the Art. Philosophical Compass, v. 3, n. 4, p. 573-589, 2008.

GIBSON, J. Interpreting Words, Interpreting Worlds. The Journal of Aesthetics and Art Criticism, v. 64 , n. 4, p. 439-450, 2006.

${ }^{40}$ KIVY, Philosophies of Arts: An Essay in Differences, 128, tradução nossa. 
KIVY, P. Philosophies of Arts: An Essay in Differences. Cambridge: Cambridge University Press, 1997.

LAMARQUE, P \& OLSON, H. Truth, Fiction, and Literature: A Philosophical Perspective. Oxford: Oxford University Press, 1994.

LEMOS, I. A Metafísica e a Semântica da Ficção: Uma Abordagem Artefactual. Tese (Doutorado) - Universidade Federal de Santa Catarina, Centro de Filosofia e Ciências Humanas, Programa de Pós-Graduação em Filosofia, Florianópolis, 2020.

MAYER, R. The Reception of a Journal of the Plague Year and the Nexus of Fiction and History in the Novel. ELH, v. 57, n. 3, p. 529-555, 1990.

ONGARATTO, S. Coronavírus: "As pessoas chegam feito peixe fora do aquário, morrendo sem ar. Pedi afastamento". Rio de Janeiro: Globo, 2020. Disponível em: <https://revistacrescer.globo.com/Familia/Saude-e-Beleza-dos-pais/noticia/2020/03/estoucom-medo-desculpa-nao-posso-seguir-em-frente-desabafa-profissional-da-saude-de-spsobre-coronavirus.html>. Acesso em: 20 de abril de 2020.

PEPINSTER, C. Daniel Defoe's Journal of the Plague Year being reprinted after selling out. Londres: The Telegraph, 2020. Disponível em: <https://www.telegraph.co.uk/news/2020/03/21/daniel-defoes-journal-plague-yearreprinted-selling/>. Acesso em: 10 de abril de 2020.

VERITY, R; OKELL, L; DORIGATTI, I; et al. Estimates of the Severity of Coronavirus Disease 2019: A Model-based Analysis. Londres: Lancet Infectious Diseases. Disponível em: <https://doi.org/10.1016/S1473-3099(20)30243-7>. Acesso em: 20 de abril de 2020.

WIGHTON, K. Individual response to COVID-19 'as important' as government action. Londres: Imperial College. Disponível em: <https://www.imperial.ac.uk/news/195976/individualresponse-covid-19-important-government-action/>. Acesso em: 20 de abril de 2020. 